\title{
The role of cannabinoids in the treatment of cancer
}

\author{
Vecera $\mathrm{L}^{1,2}$, Gabrhelik $\mathrm{T}^{3}$, Prasil $\mathrm{P}^{4}$, Stourac $\mathrm{P}^{2}$ \\ Department of Emergency Medicine, The Tomas Bata Hospital in Zlin, Zlin, Czech Republic. \\ Tomas.Gabrhelik@bnzlin.cz
}

\begin{abstract}
AIM: The aim of this review article is to summarize current knowledge about the role of cannabinoids and cannabinoid receptors in tumor disease modulation and to evaluate comprehensively the use of cannabinoids in cancer patients.

METHOD: According to the PRISMA protocol, we have included data from a total of 105 articles.

RESULTS: Cannabinoids affect cancer progression by three mechanisms. The most important mechanism is the stimulation of autophagy and affecting the signaling pathways leading to apoptosis. The most important mechanism of this process is the accumulation of ceramide. Cannabinoids also stimulate apoptosis by mechanisms independent of autophagy. Other mechanisms by which cannabinoids affect tumor growth are inhibition of tumor angiogenesis, invasiveness, metastasis, and the modulation of the anti-tumor immune response.

CONCLUSION: In addition to the symptomatic therapy of cancer patients, the antitumor effects of cannabinoids (whether in monotherapy or in combination with other cancer therapies) have promising potential in the treatment of cancer patients. More clinical trials are needed to demonstrate the antitumor effect of cannabinoids (Tab. 1, Fig. 1, Ref. 167). Text in PDF www.elis.sk. KEY WORDS: cannabinoids, cannabinoid receptor, cancer, oncological diseases, cancer treatment.
\end{abstract}

Abbreviations: $\Delta^{9}$-THC ( $\Delta^{9}$-Tetrahydrocannabinol $), 2-\mathrm{AG}$ (2-arachidonoylglycerol), ACPA (Arachidonoyl cyclopropamide), AEA (Anandamide), AKT (Protein kinase B), ALK (Anaplastic lymphoma kinase), AMPK (Adenosine monophosphate-activated protein kinase), Ang-2 (Angiopoetin 2), ATF-4 (Activating transcription factor 4), BAK (Bcl-2 homologous antagonist/killer), BAX (Bcl-2-like protein 4), Bcl-2 (B-cell lymphoma 2), BID (BH3 interacting-domain death agonist), CaCMKK $\beta$ (Calcium/ calmodulin-dependent protein kinase 2 $\beta$ ), cAMP (Cyclic adenosine monophosphate), CB1 and CB2 (Cannabinoid receptor 1 and 2), CBD (Cannabidiol), cdc42 (Cell division control protein 42 homolog), Cdk (Cyclin-dependent kinase), CHOP (CAAT/enhancebinding protein-homologous protein), JNK/c-jun (c-jun N-terminal kinase), COX-2 (Cyclooxygenase 2), CXCL12, 16 (Chemokine ligand 12, 16), CXCR4 (Chemokine receptor 4), DR (Death recep-

${ }^{1}$ Department of Emergency Medicine, The Tomas Bata Hospital in Zlin, Zlin, Czech Republic, ${ }^{2}$ Department of Paediatric Anaesthesiology and Intensive Care Medicine, Medical Faculty of Masaryk University, University Hospital Brno, Brno, Czech Republic, ${ }^{3}$ Department of Anaesthesiology, Resuscitation and Intensive Care Medicine, The Tomas Bata Hospital in Zlin, Zlin, Czech Republic, and ${ }^{4}$ Department of Anaesthesia and Intensive Care Medicine, District Hospital Amstetten, Amstetten, Austria

Address for correspondence: T. Gabrhelik, Department of Anaesthesiology, Resuscitation and Intensive Care Medicine, The Tomas Bata Hospital in Zlin, Havlickovo nabrezi 600, 76275 Zlin, Czech Republic.

Phone: +420.577552280, Fax: +420.577 .552107$

Acknowledgements: This work was supported by grant no: NV18-0300470 . tors), EGF (Epidermal growth factor), EGFR (Epidermal growth factor receptor), eIF $2 \alpha$ (Eukaryotic translation initiation factor $2 \alpha$ ), EMT (Epithelial-mesenchymal transition), ER stress (Endoplasmic reticulum stress responses), ERK (Extracellular signal-regulated kinases), ET-1 (Endothelin 1), FAAH (Fatty acid amide hydrolase), FADD (Fas-associated protein with death domain), FAK (Focal adhesion kinase), FOXO (Forkhead box O), GEFs (Guanine nucleotide exchange factors), Gi protein (Adenylate cyclase inhibitor), GPR55 (G protein-coupled receptor 55), HMG-CoA (3-hydroxy-3-methylglutaryl-coenzyme A), ICAM-1 (Intercellular adhesion molecule 1), ID1(DNA-binding protein inhibitor), IFN- $\gamma$ (Interferon gamma), IL-2, 4, 6, 8, 10 (Interleukin 2, 4, 6, 8, 10), $\mathrm{IP}_{3}$ (Inositol 1,4,5-trisphosphate), LAK (Lymphokine-activated killer), LOX (Lipooxygenase), MAGL (Monoacylglycerol lipase), MAP kinase (Mitogen-activated protein kinase), MDK (Midkine), MDSC (Myeloid-derived suppressor cells), MEK (Mitogen-activated protein kinase), MMP 2 a 9 (Matrix-metalloproteinase 2 a 9), mTOR (Mechanistic/mammalian target of rapamycin), mTORC1 a 2 (mTOR complex 1 a 2), NAGly (N-arachidonoyl glycine), NFкB (Nuclear factor $\kappa B$ ), OEA (Oleoylethanolamide), p8 (or NUPR1 (Nuclear protein-1), or Com1 (Candidate of metastasis-1), p21 (Cyclin-dependent kinase inhibitor 1), p27 (Cyclin-dependent kinase inhibitor 1B), p38 (p38 mitogen-activated protein kinase), PCNA (Proliferating cell nuclear antigen), PDGF-AA (Plateletderived grow factor), PI3K (Phosphatidylinositol 3-kinase), PlGF (Placental growth factor), PKA (Protein kinase A), PKB/AKT (Protein kinase B), PKC (Protein kinase C), PLC (Phospholipase C), PPARs (Peroxisome proliferator-activated receptors), rac1 
(Ras-related botulinum toxin substrate 1), Raf-1 (Proto-oncogene serine/threonine-protein kinase), Ras (Rat Sarcoma), ROS (Reactive oxygen species), rhoA (Ras homolog gene family, member A), SerpinE1/PAI1 (Serin protease inhibitor E1/Plasminogen activator inhibitor 1), Src (Proto-oncogene tyrosine-protein kinase), STAT3 (Signal transducer and activator of transcription 3), TCS2 (Tuberous sclerosis complex), TGF- $\beta$ (Transforming growth factor $\beta$ ), TIMP1 (Tissue inhibitor of metalloproteinase 1), TNFR (Tumor necrosis factor receptor), TRADD (Tumor necrosis factor receptor type 1-associated death domain protein), TRB3 (Tribbles homolog

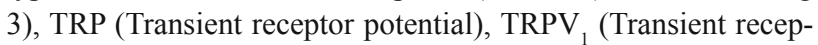
tor potential vanilloid type 1), uPA (Urokinase-type plasminogen activator), VEGF (Vascular endothelial growth factor), VEGFR-2 (VEGF receptor 2)

\section{Introduction}

The term cannabinoids includes three groups of substances. Natural phytocannabinoids, cannabis-derived substances (especially $\Delta^{9}$-THC a CBD), synthetically prepared analogs and endocannabinoids anandamide (AEA) (1) and 2arachidonoylglycerol (2-AG) $(2,3)$ which are naturally found in the human body. Cannabinoids bind to two specific receptors - CB1 and CB2 $(4,5)$ and further to potential cannabinoid receptors (6). Each cannabinoid has a different affinity and intrinsic activity for cannabinoid and potential cannabinoid receptors. Therefore different cannabinoids may have another clinical effect. In the treatment of an oncologically ill patient, cannabinoids are used primarily for symptomatic treatment (pain, nausea, vomiting, and anorexia) (7). In the pain management, cannabinoids are effective for chronic neuropathic pain (7), their synergistic effect with opioids is assumed (8), although they do not appear to have any effect on the treatment of acute pain (9). Recently, we have seen publications that consider the direct antitumor effect of cannabinoids and the involvement of cannabinoid receptors in curative therapy of an oncologically ill patient. Anti-proliferative, antimetastatic, antiangiogenic, and proapoptotic effects of cannabinoids are considered (7). In this review article, we will focus on the role of cannabinoids as antitumor agents. Symptomatic treatment and pain management will be mentioned too. In our article, we evaluate in detail the effect of cannabinoids on all the receptors they can influence. Table 1 provides a complete list of studies published so far on this topic.

\section{Materials and methods}

The search algorithm proceeded according to the PRISMA protocol. In the Pubmed.org database, 980 citations were initially identified. The search terms strings was "Cannabinoid AND cancer" and "Cannabinoid AND tumor." We found 177 citations related to the topic. After excluding duplicates $(\mathrm{n}=32)$, articles that were not in English $(n=6)$, and articles without full text $(n=34)$, a total of 105 full-text articles were included. Of these, nineteen articles were systematic reviews, eighty-five articles were animal or cell culture studies, and only one article was a clinical trial. The search diagram is shown in Figure 1.

\section{Results}

\section{Cannabinoid receptors}

Since the 1990s, two types of cannabinoid receptors, CB1 and CB2 $(4,5)$, have been known, and other receptors (TRPV1, PPARs, GPR55, GPR119, and GPR18) have been identified as potential cannabinoid receptors $(6,10,11)$. Both cannabinoid receptors are associated with $\mathrm{G}$ proteins. The $\mathrm{CB} 1$ receptor is mainly found in the nerve tissue, while the $\mathrm{CB} 2$ receptor is mainly found on immune cells (12). The endocannabinoid system plays an important regulatory role in the secretion of hormones, reproductive functions, and stress reactions (13). The metabolism of endocannabinoids, ligands of cannabinoid receptor, is mainly mediated by lipase hydrolysis. AEA hydrolyzes FAAH (14) primarily, 2-AG hydrolyzes MAGL (15). CB1 receptors are mainly found on central and peripheral nervous system cells, and their function is primarily in inhibiting the release of neurotransmitters. It can also be found on pituitary cells, reproductive organs, and immune cells. This receptor is a heterodimer linked to $\mathrm{G}_{\mathrm{i}}$ protein. Upon activation of the $\mathrm{CB} 1 \mathrm{re}-$ ceptor, inhibition of adenylate cyclase and decrease of intracellular concentration of cAMP results in an increase in the activity of the regulatory mechanisms that belong to the MAP kinase cascade (16). Rarely, the $\mathrm{CB} 1$ receptor may be associated with a $\mathrm{G}_{\mathrm{s}}$ protein, which in turn increases the activity of adenylate cyclase (12). Reduction of cAMP directly works by reducing the potassium influx via $\mathrm{K}_{\text {ir }}^{+}$channel and increased calcium efflux through the $\mathrm{N}$ and $\mathrm{P} / \mathrm{Q}$ $\mathrm{Ca}^{2+}$ channel. Further reactions occur by activating PKA and PKC. Activated PKA affects the decrease in potassium efflux in the $\mathrm{K}_{\mathrm{A}}^{+}$ channel. PKC directly phosphorylates the $\mathrm{CB} 1$ receptor causing dissociation of the receptor from the ion channels $\left(\mathrm{K}^{+}\right.$ir and $\mathrm{N}$ and $\mathrm{P} / \mathrm{Q}$ type $\mathrm{Ca}^{2+}$ ), which leads to the reduction in the direct effect of CB1 on these channels (negative feedback). Another mechanism is the activation of intracellular signal kinases belonging to a large family of MAP kinase cascades (Ras/Raf-1/MEK/ERK, FAK, p38, c-jun) (13). These intracellular signal kinases play an important role in cell differentiation, proliferation, and cell death (16). The last mechanism is the inhibition of the PI3K/AKT/mTOR pathway - a very important pathway that promotes cell growth and inhibits apoptosis (17) by stimulating growth factors.

Unlike the $\mathrm{CB} 1$ receptor, $\mathrm{CB} 2$ receptors are found primarily on cells of the immune system. CB2 receptors have been found on all cells of the immune system. Only in neutrophils, there is an unclear consensus on whether they express CB2 receptors (18). Furthermore, CB2 receptors are expressed on tonsils, spleen, and thymus. Further, CB2 receptors have been found on pancreatic, renal, uterine, and genital cells (18). CB2 receptors are primarily involved in the modulation of the inflammatory response and cytokine release $(12,18)$. Although CB2 receptors are functionally similar to $\mathrm{CB} 1$ receptors, there are some differences between the two. The activation of $\mathrm{CB} 2$ receptors leads to four basic cellular processes. The basal pathway, as with the $\mathrm{CB} 1$ receptors, is associated with the $\mathrm{G}_{\mathrm{i}}$ protein and the adenylate cyclase activity is reduced. It is followed by ERK activation of the MAP kinase, which is probably mediated by PKC (19). CB2 receptor agonists increase the release of $\mathrm{Ca}^{2+}$ from the endoplasmic reticulum and 


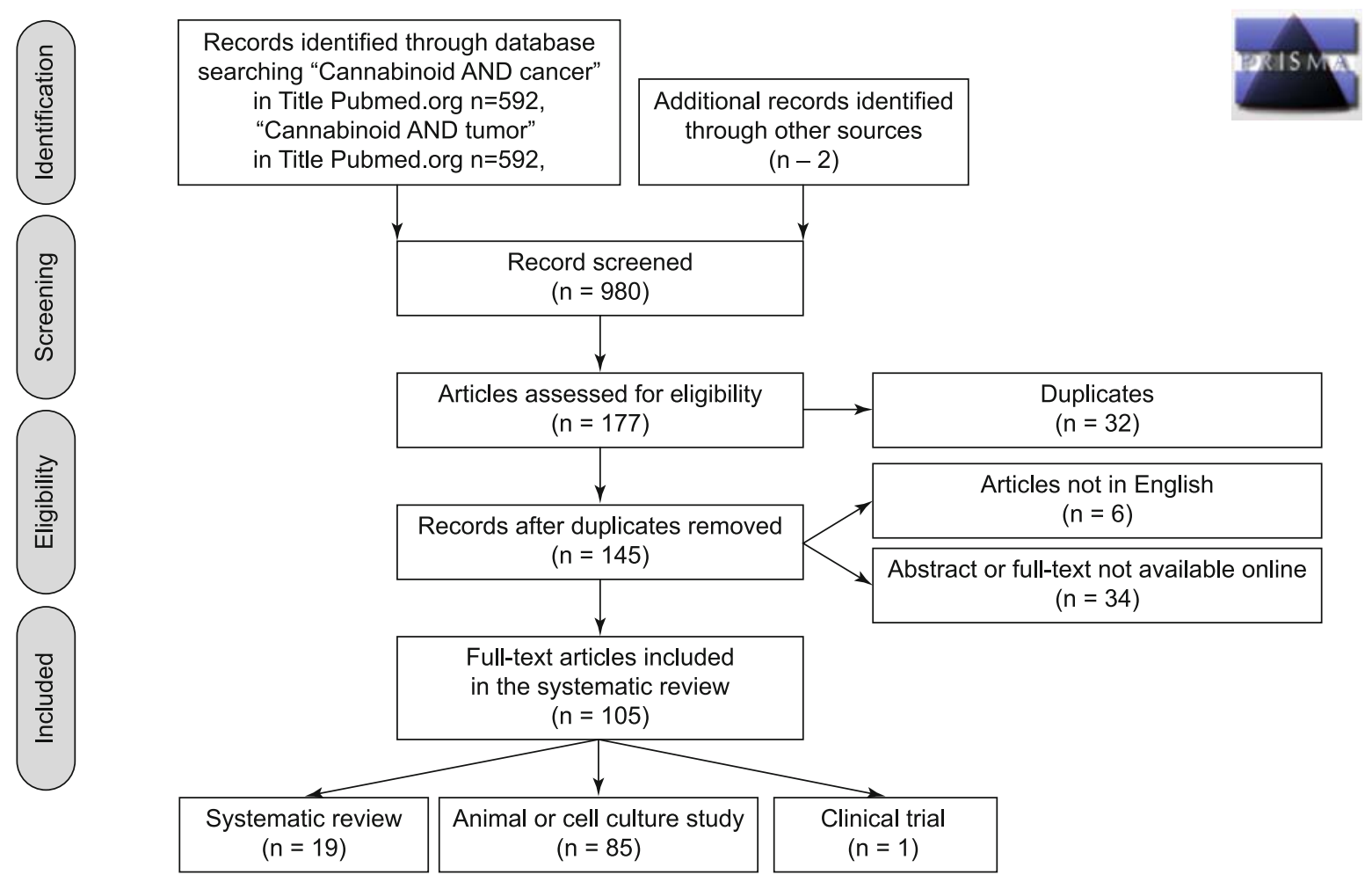

Fig. 1. Data search diagram.

increase the mitochondrial $\mathrm{Ca}^{2+}$ via the PLC-IP3 signaling pathway. This leads to an increase in intracellular $\mathrm{Ca}^{2+}$ concentration (20). Unlike CB1 receptors, it appears that CB2 receptors are not associated with potassium channels, which is probably the most important difference between the two receptors causing them to be functionally different (18). It is very interesting that the two main endocannabinoids, i.e. 2-AG and AEA, evoke distinct functions after binding to the $\mathrm{CB} 2$ receptor. After the 2-AG binding, a pro-inflammatory response (increased recruitment, migration, adhesion of leukocytes, the release of chemokines) occurs. On the other hand, binding of AEA to $\mathrm{CB} 2$ receptor results in an antiinflammatory response (reduced release of proinflammatory cytokines, increased production of anti-inflammatory IL-10, reduced nitric oxide production) (18).

Another potential cannabinoid receptor is $\operatorname{GPR} 55(10,11)$. GPR55 is associated with the $\mathrm{G}_{13}$ protein (guanine nucleotide-binding protein alpha 13). It is considered that GPR55 will be included in the cannabinoid receptor family and will be named CB3 (21). This G-protein regulates cellular processes via GEFs, a protein that activates GTPases. The activation occurs by GEFs changing GTPs to GDPs on the GTPase. Activated GTPase coupled GTP is prepared to phosphorylate various cellular signaling pathways (22).

The $\mathrm{G}_{13}$ subtype is essential for inducing the migration of fibroblasts and endothelial cells (23). Activation of GPR55 leads to stimulation of rhoA, cdc42, and rac1 (24). It is important that all three of the aforementioned proteins (rhoA, cdc42, and rac1) are included in signal cascades regulating cell division, cell growth and migration, and thus all three may play a role in the progression of an oncological disease $(25,26,27)$. In addition to GPR55, there is a large number of G-protein coupled receptors that potentially can be activated by cannabinoids (6). The most important of these receptors are GPR119 and GPR18. GPR119 is a receptor that occurs primarily in cells of the gastrointestinal tract and pancreas. GPR119 is an important receptor in the regulation of insulin secretion and energy balance $(6,10)$. Its association with the endocannabinoid system is considered because OEA, a potential endocannabinoid, has an affinity for GPR119 (28). However, its involvement in the endocannabinoid system is highly questioned (6). GPR18 is considered to be an abnormal cannabinoid receptor regulating the migration and proliferation of microglia. This effect is mediated through NAGly (11).

An interesting group of receptors potentially belonging to the family of endocannabinoid receptors is a large superfamily TRP (6). These are non-selective cation channels including the six subgroups: "canonical," "vanilloid (TRPV)," "melastatin (TRPM)," "polycystin," "mucolipin”, and “ankyrin (TRPA).” These receptors are involved in the transmission of a number of stimuli - temperature, light, taste and olfactory stimuli, mechanical stimuli, osmotic stimuli (29). Currently, several receptors from this so-called superfamily are considered, which could be part of the endocannabinoid system - TRPV1, TRPV2, TRPV4, TRPM8, and TRPA1 (6). The most important of these groups is TRPV1, a capsaicin receptor. This non-selective cation channel, which (for example) regulates the intracellular $\mathrm{Ca}^{2+}$ movement and its release from the 
79-95

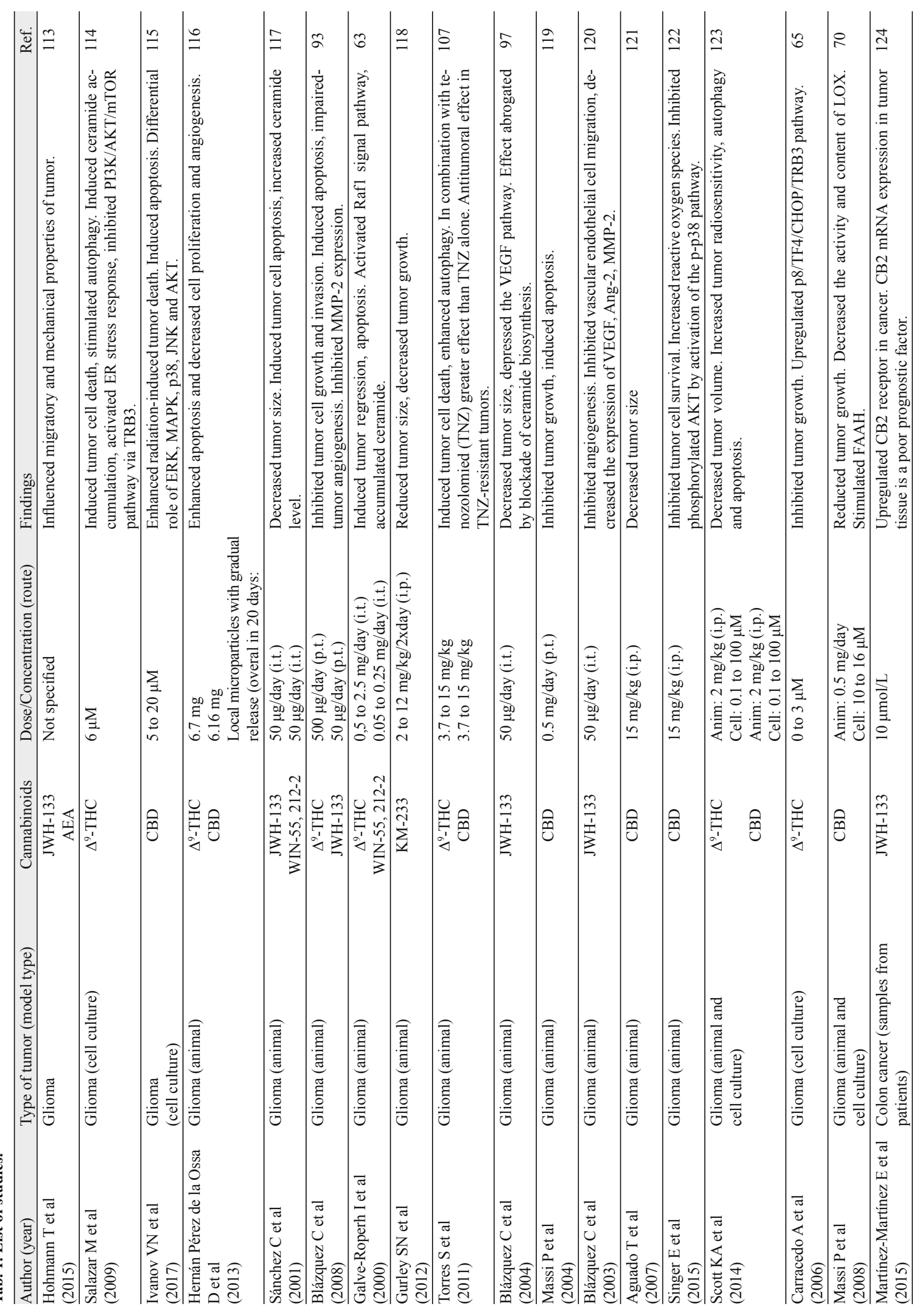




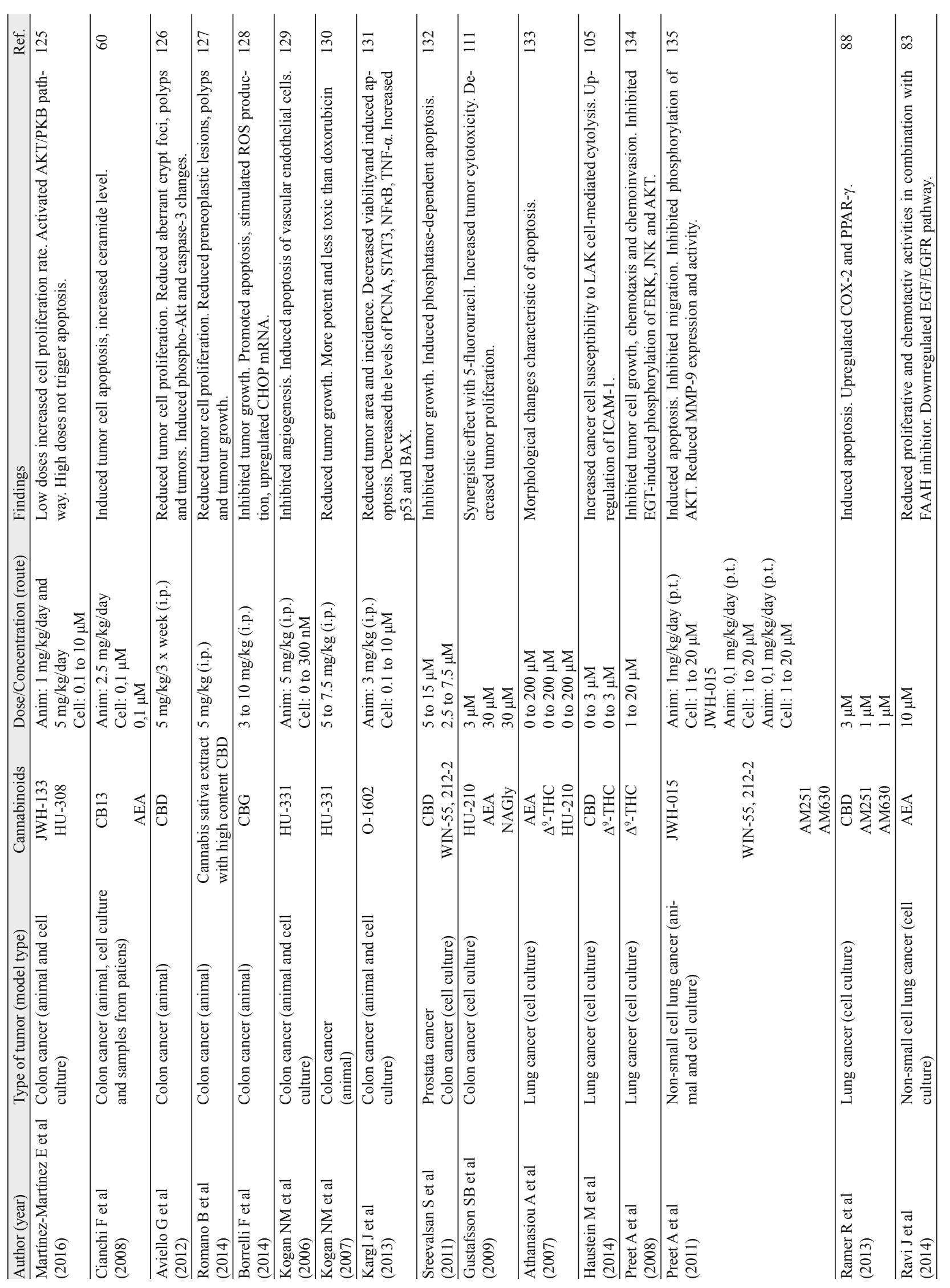


79-95

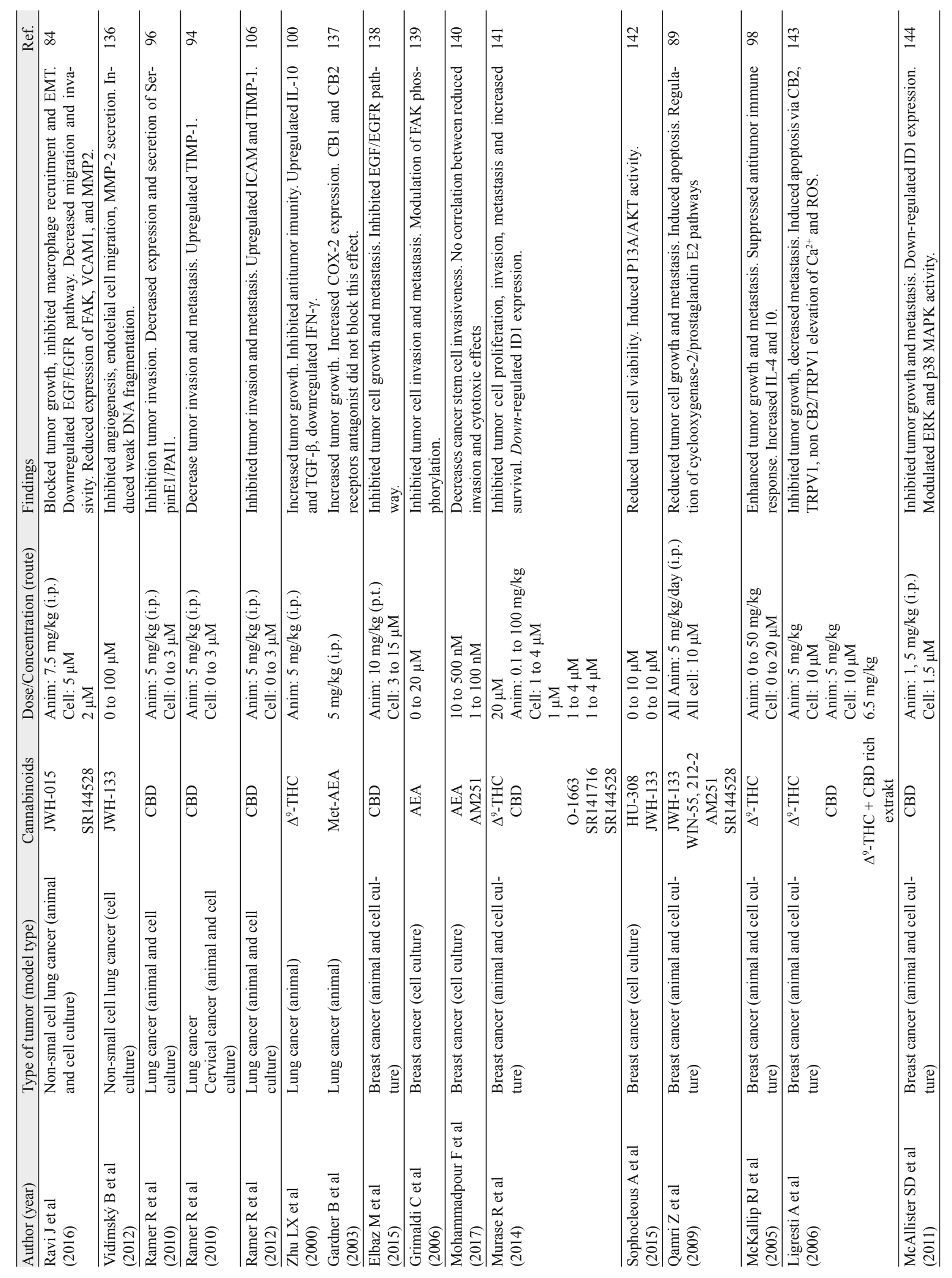




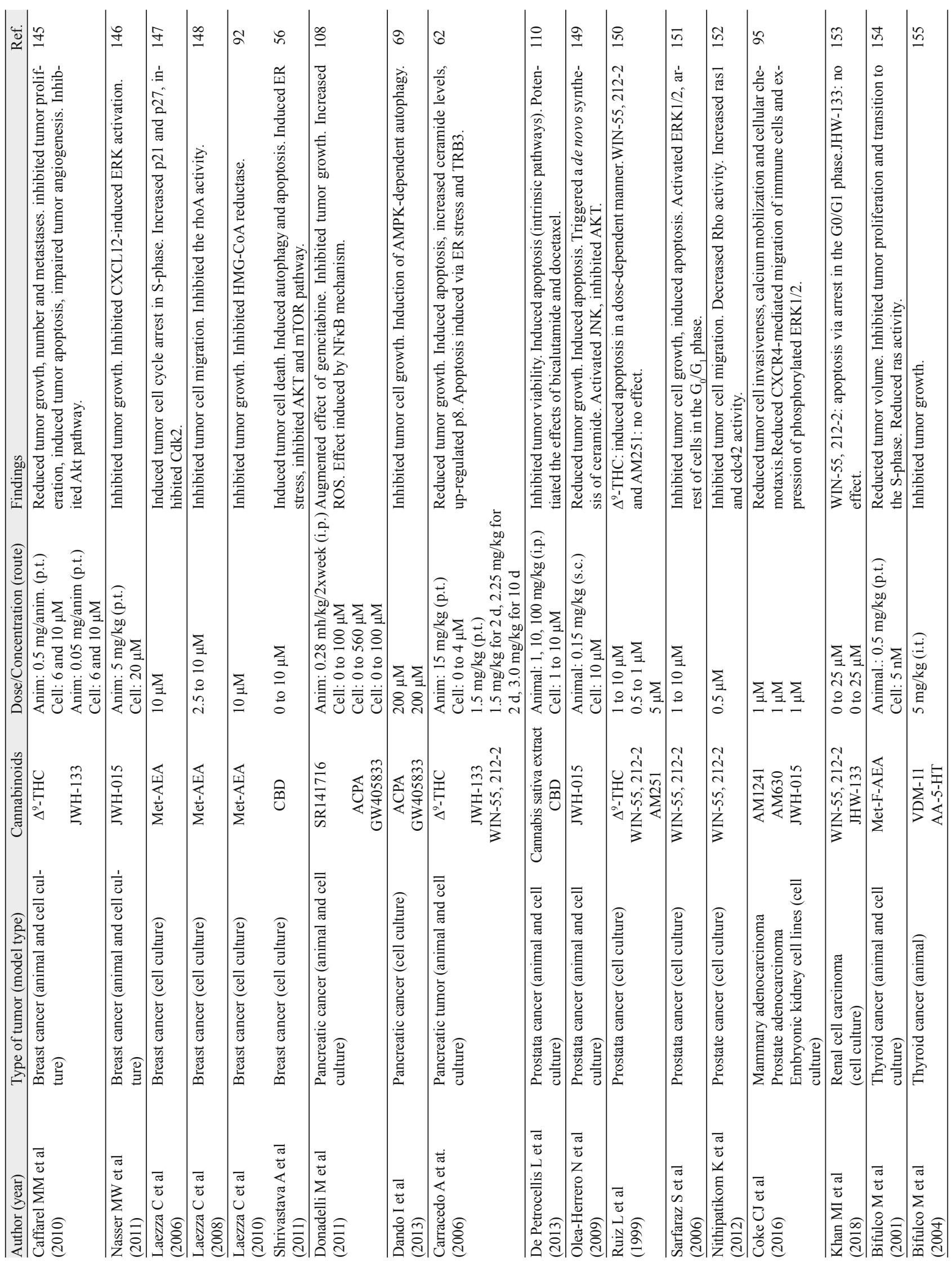


79-95

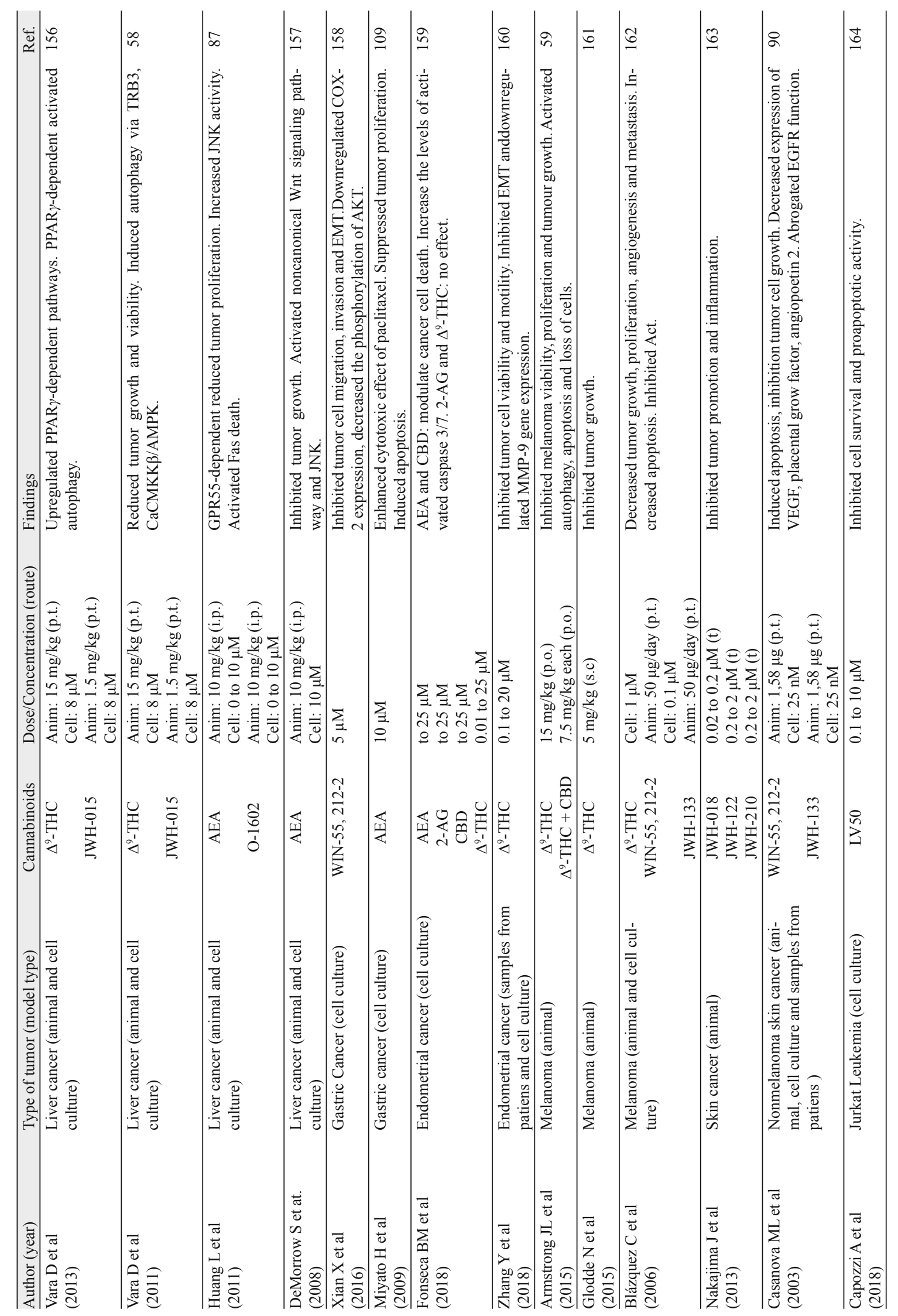


endoplasmic reticulum (30), can activate, in addition to cannabinoids, a variety of exogenous and endogenic stimuli - capsaicin (component of chili pepper), allyl isothiocyanate (constituent of mustard and wasabi), temperature above $43{ }^{\circ} \mathrm{C}$, acidic environment $(6,31)$. TRPV1 are found primarily on non-myelinated and weakly myelinated type $\mathrm{C}$ and $\mathrm{A} \delta$ neural fibrils of the peripheral nervous system and therefore are included in pain modulation. Furthermore, TRPV1 is found in CNS cells but also other cells (epithelium, endothelium, glia, immune cells, osteoclasts, hepatocytes, fibroblasts, etc.) (32). Activation of TRPV1 receptors leads to a number of functions - increased intracellular $\mathrm{Ca}^{2+}$ concentration, increased cation flow in neurons, increased release of vasoactive peptides in nerve fibers. It is also very important that several stimuli can increase or decrease the sensitivity of TRVP1 receptors. Modulations of receptor function by inflammation, protein kinase phosphorylation, temperature, $\mathrm{pH}$, membrane potential, etc. are also important (6). Interestingly, anandamide binds to the same binding site as capsaicin, but the activation of the TRVP1 receptor by temperature or $\mathrm{pH}$ is at another site of the receptor (33).

Another potential part of the endocannabinoid system is the group of ligand-activated transcription factors and nuclear receptors collectively called PPARs. These are three isoforms of PPAR $\alpha, \operatorname{PPAR} \beta$, and PPAR $\gamma$. They are activated by fatty acid derivatives (prostaglandins, leukotrienes), but PPARs function more like general lipid sensors that monitor local changes in metabolism. PPAR $\alpha$ is clinically affected by the action of fibrates (gemfibrozil and fenofibrate), PPAR $\gamma$ is the target of thiazolidinediones (pioglitazone, rosiglitazone, and troglitazone). These receptors are expressed primarily in the liver, PPAR $\alpha$ in skeletal muscles and PPAR $\gamma$ in adipose tissue. A number of cannabinoid agonists are also PPARs agonists. However, the potential of cannabinoids to activate PPARs is relatively small compared to their potential to activate $\mathrm{CB} 1$ and $\mathrm{CB} 2$ receptors (6).

In addition to the aforementioned receptors, cannabinoids can be used to modulate the functions of many important receptors such as opioid, acetylcholine, serotonin, glycine receptors, and others (6).

Cannabinoids in the treatment of pain and as a symptomatic treatment of cancer patients

The cannabinoid receptor system, their ligands and metabolizing enzymes regulate pain at all levels - supraspinal, spinal, and peripheral. The analgesic effect is mediated not only by binding to CB1 and CB2 receptors, but also to the reduction of endocannabinoid catabolism and uptake, and affecting other receptor systems (TRPV1, GPR55, PPARs, and opioid receptors). Cannabinoid-mediated pain modulation involves a number of mechanisms - inhibiting the release of presynaptic neurotransmitters and neuropeptides, modulating the postsynaptic excitability of neurons, activating the descendant inhibitory system, and influencing the inflammatory response in the nervous system (34). For this reason, we find some potential in the use of cannabinoids in the treatment of pain. Cannabinoids have the greatest effect on the treatment of allodynia, neuropathic pain, medication-rebound headache, and chronic oncological pain. The treatment of acute pain with cannabinoids is not superior to 
non-opioid analgesia, and the treatment of cancer-related pain by cannabinoids provides only a mild analgesic effect (35). However, the data on the efficacy of cannabinoids in neuropathic pain are inconsistent, as well as the data on safety and good tolerability of these drugs in the treatment of any chronic pain (36). The Canadian Pain Society has recently recommended cannabinoids as third-line drugs for the treatment of chronic neuropathic pain (37). Additionally, the German and Israeli Pain Society recommends the use of cannabinoids as third-line drugs in the treatment of chronic pain (38). At the supraspinal level, stimulation of the CB1 receptor has a significant analgesic effect. In the murine model, supraspinal administration of selective $\mathrm{CB} 1$ receptor agonist VDhemopressin $(\alpha)$ has a significant dose-dependent effect. This effect is significantly reduced by the administration of the CB1 receptor antagonist. Furthermore, it appears that stimulation of the TRVP1 receptor can play a role in this analgesic effect (39). Cannabinoid receptor agonists increase the analgesic effect of opioid receptor agonists (e.g. morphine). The addition of cannabinoid receptor agonists significantly and dose-dependently increases the analgesic effect of the $\mu$-opioid agonists. However, this analgesic effect is different for various cannabinoid receptor agonists. The addition of CP55.94 to morphine has a greater effect than adding $\Delta^{9}$-THC. This finding is important for designing mixtures combining cannabinoids and opiates (40).

The effect of cannabinoids in the treatment of anorexia in patients with advanced tumors is controversial. It is unclear whether cannabinoids have a positive effect on weight gain or appetite. The level of evidence on this issue is very low (41).

At present, it is not conclusively proven that cannabinoids have an effect on the reduction of chemotherapy-induced nausea and vomiting (42). However, they appear to have a greater effect on the suppression of nausea and vomiting compared to placebo and they have the same effect compared to prochlorperazine. The combination of cannabinoids and other antiemetic drugs does not add additive effects and is associated with a greater number of undesirable effects (cognitive impairment, drowsiness) (43). Based on these data, the use of cannabinoids in the treatment of chemotherapy-induced nausea and vomiting cannot be unambiguously encouraged or rejected.

In conclusion, cannabinoids are effective in the treatment of pain in adults and may have an effect on the treatment of chemotherapy-induced nausea and vomiting (44).

\section{Cannabinoids as antitumor therapies}

Cannabinoids as antitumor treatment can work by three types of mechanisms. The first is the stimulation of cell death by the mechanism of autophagy, apoptosis mediated by autophagy, and influencing signaling pathway leading to apoptosis. The second group is the inhibition of tumor angiogenesis, invasiveness, and metastasis. The third mechanism is the modulation of the antitumor immune response $(45,46,47,48,49,50,51,52)$.

\section{Stimulation of cell death}

Basic signaling pathways of cannabinoid receptors influencing differentiation, proliferation, and cell death have been outlined in the section on cannabinoid receptors. At this point, we will focus on two main mechanisms by which cannabinoids lead to the stimulation of cell death, namely autophagy and apoptosis.

\section{Autophagy}

This is an old evolutionary process that involves the packaging of cellular organelles by a two-membrane bag called autophagosome. In the second step, the autophagosome merges with lysosomes, leading to the degradation of cellular organelles (53). Although autophagy is primarily cytoprotective, it can also trigger apoptosis (54). Interestingly, autophagy may be a protection from apoptosis on the one hand, but on the other hand, it acts as an alternative pathway inducing apoptosis (55). A Beclin-1 protein plays a key role in the process of autophagy and apoptosis. This protein blocks autophagy when bound to the Bcl-2 protein complex, Bcl-2 proteins are key proteins in the regulation of apoptosis. If the Beclin-1/Bcl-2 complex is cleaved (e.g. caspases), autophagy is induced. In addition, fission products of this complex enter mitochondria and stimulate cytochrome $\mathrm{c}$ and induce apoptosis (56). Cannabinoids induce autophagy by two mechanisms, both of which lead to the inhibition of the autophagy key axis (PI3K/AKT/mTOR signaling pathway (see CB1 receptor)). Autophagy appears to be a key mechanism of antitumor action of cannabinoids. It is also important that apoptosis is blocked by blocking autophagy, but blocking apoptosis itself does not block cannabinoid-induced autophagy. It is clear from this observation that autophagy not only precedes and stimulates apoptosis, but is essential for cannabinoid-induced apoptosis $(57,58,59)$. The most important mechanism by which cannabinoids induce autophagy is the accumulation of ceramide in tumor cells. Ceramide is a sphingolipid composed of sphingosine and fatty acids, and it is a major component of cell membranes. Cannabinoids increase ceramide concentration in the cell by two mechanisms. The first is the hydrolysis of sphingomyelin by the sphingomyelinase enzyme, thus creating ceramide only when activating the $\mathrm{CB} 1$ receptor. The second is de novo synthesis of ceramide with the enzyme serine-palmitoyl transferase (SPT) which generates ceramide by activating both $\mathrm{CB} 1$ and $\mathrm{CB} 2$ receptors (60). The accumulation of ceramide in the cell stimulates the stress response of the endoplasmic reticulum (ER stress). ER stress results in increased phosphorylation of eIF $2 \alpha$, resulting in up-regulation of $\mathrm{p} 8$ protein, followed by the activation of transcription factors (ATF-4, CHOP) leading to the activation of TRB3. Between these proteins and transcription factors, there is a series of feedback circuits. TRB3 subsequently inhibits the PI3K/AKT/mTOR signal pathway at a level between mTORC 2 and ACT $(57,58,60,61,62,63,64,65$, $66,67)$. The signaling pathway $\mathrm{p} 8 / \mathrm{ATF} 4 / \mathrm{CHOP} / \mathrm{TRB} 3$, followed by the inhibition of the PI3K/AKT/mTOR cascade, is probably the most important antitumoral mechanism of cannabinoids (45, $57,58)$. The second signaling pathway by that cannabinoids activate autophagy by inhibiting the $\mathrm{PI} 3 \mathrm{~K} / \mathrm{AKT} / \mathrm{mTOR}$ pathway is the activation of $\mathrm{CaCMKK} \beta$. This protein kinase, like the previous signaling pathway, is activated by ER stress. The next stage is the activation of AMPK, which directly phosphorylates and activates TCS2, the major direct inhibitor of mTORC1. The mTORC1 
has a large anti-autophagic effect. Therefore, the inactivation of mTORC1 (ceramide, ER stress) leads to increased autophagy (68). This mechanism was observed in hepatocellular carcinoma cells and was activated only by CB2. The induction of autophagy by AMPK was also observed in pancreatic carcinoma cells (69). Both signaling pathways that inactivate $\mathrm{PI} 3 \mathrm{~K} / \mathrm{AKT} / \mathrm{mTOR}$ run independently of each other and regulate autophagy at different stages (58). It seems that cannabidiol can activate autophagy and apoptosis by mechanisms independent of CB receptors. This mechanism is partly explained by increased formation of reactive oxygen species, the reduction of LOX activity, and subsequent stimulation of autophagy and apoptosis $(56,70)$. A key protein in the activation of cannabidiol-induced autophagy and apoptosis is the aforementioned Beclin-1 protein (56).

\section{Apoptosis}

In addition to activating apoptosis via autophagy, cannabinoids stimulate apoptosis with several mechanisms independent of autophagy. Apoptosis can be induced in two ways. The first is an external pathway that begins with the activation of death receptors (TNFR, FAS). The ligands of these receptors via the TRADD/FASS pathway initiate the caspase pathway (caspase 8 and 3) leading to apoptosis (71). The second is an internal pathway that starts with the activation of the Bcl-2 receptors mitochondrial family (BID, BAK, BAX). An important part is the cytoplasmic protein BID, which contains the $\mathrm{BH} 3$ domain and cleaves it to produce truncated BID (tBID), resulting in the activation of BAX and BAD mitochondrial proteins and, subsequently, the activation of cytochrome c and caspase 9, which stimulates apoptosis. The outer and inner paths are interconnected by caspase 8 (72).

The signal pathway PI3K/AKT/mTOR activates apoptosis by several mechanisms. The first mechanism is to modulate the inhibition of two important Cdk inhibitors, namely p21 and p27, modulation of which is mediated by AKT and $\operatorname{FOXO}(73,74,75)$. If AKT phosphorylates FOXO, the transition of FOXO to the cell nucleus is prevented. However, if FOXO is dephosphorylated, it passes into the cell nucleus and acts as a transcription factor stimulating the expression of p21 and p27 (76). The Cdk-cyclin complex is a very important cell cycle stimulator, inactivating it by stopping the cell cycle in phase $\mathrm{G}$, which subsequently stimulates apoptosis. The second mechanism by which the PI3K/AKT/ mTOR pathway initiates apoptosis is the modulation of the already mentioned inner pathway of apoptosis activation. AKT directly inhibits the pro-apoptotic proteins of the Bcl-2 family (BAD) by enhancing the phosphorylation of these proteins, i.e. AKT inhibition induced by cannabinoids leads to BAD activation and subsequent apoptosis (77).

Very important pathways that regulate apoptosis are signaling pathways involved in a large family of MAP kinases (Ras/Raf-1/ MEK/ERK, c-jun (JNK), p38). Cannabinoids regulate apoptosis and stimulate these signaling pathways. The already mentioned increased production of ceramide results in the activation of the Ras/Raf-1/MEK/ERK signaling pathway. This pathway is associated primarily with EGFR and other growth factor receptors (51, $60)$. The binding of the ligand to the growth factor receptor leads primarily to the activation of the RAS family, which are small GTPases that exchange GDP for GTP, leading to the phosphorylation of RAF-1, MEK, and ERK. This signaling pathway increases the production of various transcription factors (c-fos...) and modulates the processes of apoptosis and cell cycle $(78,79)$. Also, the potential cannabinoid receptor GPR55 acts by Ras/Raf-1/MEK/ ERK and JNK modulation $(30,80,81)$. However, it appears that the EGFR/ERK signaling pathway leads to the inhibition of the p8/ATF4/CHOP/TRB3 signaling pathway and, consequently, to increased activities of the PI3K/AKT/mTOR signaling pathway and the inhibition of apoptosis and tumor cell resistance to cannabinoids (82). However, there is a work that shows that cannabinoids can also lead to the downregulation of the EGF/EGFR signaling pathway and subsequently stimulate tumor cell apoptosis $(83,84)$. This effect is further stimulated by the action of FAAH inhibitors (83). EGF/EGFR pathway downregulation also leads to the inhibition of macrophage recruitment and EMT inhibition, further reducing the progression of tumor growth (84).

Another proapoptotic signaling pathway that cannabinoids can modulate is the induction of cell death by interacting with receptors belonging to the TNFR family. These receptors belong to the group of the so-called death receptors (DR) which seek the outer pathway of activating apoptosis. It has been shown that the use of cannabinoids increases the sensitivity of tumor cells to DR ligands. This synergistic effect may be the basis for the joint use of cannabinoids and DR ligands for the treatment of oncological patients $(60,85)$. Cannabinoids modulate both (external and internal) pathways of apoptosis activation.

Cannabinoids activate apoptosis by mechanisms independent of $\mathrm{CB} 1$ and $\mathrm{CB} 2$ receptors. Activation of the GPR55 receptor results in the recruitment of FAS, DR, and activation of the JNK signaling pathway $(30,86,87)$. Also, through the activation of PPARs and TRPV, cannabinoids modulate apoptosis (30). Another mechanism by which cannabinoids can induce apoptosis is the activation of the COX-2 signaling pathway $(88,89)$.

\section{Inhibition of angiogenesis, invasiveness, and metastasis}

The major proangiogenic factors that are inhibited by cannabinoids are VEGF, PLGF, Ang-2 $(90,91)$. The process of angiogenesis is extremely complex and involves the chemotaxis of endothelial cells, their migration, invasion, and proliferation into the target tissue, differentiation into tubular capillaries and basal membrane production. CBD modulates the process of angiogenesis without affecting endothelial cell apoptosis or necrosis (90). A key signaling cascade of angiogenesis that is affected by CB1 and $\mathrm{CB} 2$ receptor agonists is the $\mathrm{rho} / \mathrm{FAK} / \mathrm{Src}$ signaling pathway. This signaling pathway plays a key role not only in angiogenesis, but also in cell adhesion and cell migration (51). A key factor in this pathway is rhoA, which exists in two states - inactive, in which GDP is bound to rhoA and active, in which GTP is bound to rhoA. When rhoA is in the active state, it phosphorylates FAK thereby progressively reducing the formation of VEGF, PGF and Ang-2 $(51,92)$, which results in decreased activation of VEGFR-2.

Cannabinoids inhibit the expression of two important proteases, namely MMP2 and MMP9. These proteases play an important 
role in the extracellular matrix and basal membrane remodeling process. Furthermore, cannabinoids also affect TIMP1 expression. TIMP1 has a dual function in the body. First, it is a metalloproteinase inhibitor, but it also affects tumor proliferation and angiogenesis by mechanisms independent of $\operatorname{MMP}(91,93,94)$. In addition to these mechanisms, cannabinoids also interfere with a number of other signaling pathways (CXCL16, CXCR4, IL-8, ET-1, SerpinE1/PAI1, uPA, PDGF-AA). These factors play an important role in the process of angiogenesis, invasiveness, adhesion, and extracellular matrix degradation $(87,95,96)$.

Very important is the finding that influencing angiogenesis by decreasing VEGF production and decreasing activation of VEGFR-2 occurs via the ceramide/p8 pathway (97). Also, inhibition of MMP2 and MMP9 is likely to occur via the ceramide/p8 pathway (93). As mentioned above, this finding also supports the theory that the influence of de novo ceramide synthesis is probably a key mechanism in the antitumor effect of cannabinoids.

\section{Modulation of the antitumor immune response of cannabinoids}

The antitumor effect of cannabinoids can also be caused by an antitumor immune response. However, current data show that cannabinoids rather reduce the effectiveness of the antitumor immune response and thus lead to the progression of tumor growth and metastasis. It is believed that the anticancer immune response is primarily mediated by Th1 lymphocytes. On the other hand, the increase in Th2 lymphocytes leads to the stimulation of tumor growth. Cannabinoids can lead to increased production of IL-4, IL-6, IL-10, and TGF- $\beta$, which are interleukins increasing Th2 lymphocyte production and, on the other hand, cannabinoids reduce IL- 2 and IFN- $\gamma$ production. This effect is due to the activation of CB2 receptors $(98,99,100)$. Little is known about the effect of cannabinoids on NK cells. However, it is believed that cannabinoids reduce the antitumoral effect of NK cells (98). Furthermore, cannabinoids lead to increased production of MDSC, cells which suppress the cytotoxic activity of NK cells and T lymphocytes. This effect of cannabinoids is mediated by the transcription factor of PPAR $\gamma(101,102)$. On the other hand, some data show that this immunosuppressive effect of cannabinoids can prevent some types of cancer from occurring by suppressing chronic inflammation (103). However, this effect will only manifest with the long-term use of cannabinoids. MAGL deficiency supports CB2-dependent and TLR4 receptor-dependent macrophage activity that suppresses CD8+ T cell function. Treatment of CB2 antagonist slows the progression of tumor growth (104).

It must be said that this pronounced immunosuppressive effect of cannabinoids, which reduces antitumor immune surveillance, seems to be the biggest problem in the clinical use of cannabinoids as antitumor drugs. The solution would be to use selective CB1 receptor agonists and $\mathrm{CB} 2$ receptor antagonists in the treatment of cancer patients.

For completeness, it is to be noted that cannabinoids lead to increased ICAM-1 expression, thereby increasing the susceptibility of tumor cells to LAK, leading to the cytolysis of tumor cells (105). By way of activation of ICAM-1, cannabinoids also reduce tumor cell invasiveness and metastasis (106).

\section{Combination of cannabinoids with other anticancer treatments}

Cannabinoids have a certain effect on tumor cells that are highly resistant to routine chemotherapy. This mechanism may be due to the fact that the administration of cannabinoids with other chemotherapy or radiotherapy increases the sensitivity of tumor cells to antitumor therapy $(45,46,47,48,49,50,51,52)$. Cannabinoids are believed to have a synergistic effect with antitumoral chemotherapy and radiotherapy (45). The most studied and cited is a combination of cannabinoids with temozolomide, a chemotherapeutic agent used to treat brain tumors, especially glioblastoma multiforme. It has been shown that the therapy of glioblastoma multiforme with small doses of cannabinoids and temozolomide has a much greater antitumor effect than the use of both substances alone (107). In addition to temozolomide, it has been shown that cannabinoids have a synergistic effect with gemcitabine (108), paclitaxel (109), docetaxel (110), and 5-fluorouracil (111).

The combination of cannabinoids with other chemotherapeutics is advantageous in glioblastomas that are primarily resistant to the antitumor effect of cannabinoids. The antitumor effect of cannabinoids against glioblastoma cells is primarily mediated by autophagy (see above).

Some types of glioblastomas show resistance to cannabinoids, which is likely to be due to increased expression of the MDK gene. The product of this gene is MDK protein activating ALK. Activation of ALK dramatically reduces cannabinoid-mediated autophagy. Therefore, a combination of cannabinoids with MDK/ ALK-inhibiting substances could have a major effect on enhancing autophagy and thus the antitumoral effect of cannabinoids (112).

However, the MDK/ALK signaling pathway is not the only one that inhibits cannabinoid-mediated autophagy in glioblastoma. Increased expression of amphiregulin, a protein belonging to a large EGF family, results in increased activation of the EGFR/ ERK signaling pathway. As mentioned, this signaling pathway inhibits the p8/ATF4/CHOP/TRB3 signaling pathway and subsequently increases PI3K/AKT/mTOR signaling pathway to inhibit autophagy and apoptosis (82).

The use of MDK/ALK and EGFR/ERK signaling pathway inhibitors in combination with cannabinoids could have a great effect in the treatment of glioblastoma (46).

\section{Discussion}

Cannabinoids (phytocannabinoids and synthetic cannabinoids) have a promising potential in the treatment of cancer patients. Apart from symptomatic treatment (nausea, pain, anorexia), where cannabinoids mainly affect chronic pain, their antitumor effect may also be applied. The main mechanism of action is the activation of autophagy and subsequent stimulation of tumor cell apoptosis. Autophagy is primarily activated by the accumulation of ceramide in the tumor cell. If we consider cannabinoids as an antitumor treatment, we need to consider several factors. Cannabinoids affect not only $\mathrm{CB} 1$ and $\mathrm{CB} 2$ receptors, but can also affect many other receptors (GPR55, TRP, PPARs). Therefore, it is very important to know what the expression of all cannabinoid receptors is - not only on tumor cells but also on cells of the immune system. It is 
also necessary to take into account the effect of epigenetics, which means which signaling pathways (p8-TRB3, AKT, AMPK, CKD, MDK/ALK, etc.) are active in the tumor. There is a great deal of influence on the choice of cannabinoid where the different affinity and intrinsic activity of cannabinoids on cannabinoid receptors can lead to different effects in a particular tumor. Therefore, the question is whether to focus on the Cannabis sativa extract, which contains the combination of $\Delta^{9}$-THC, CBD, and other cannabinoids, or to use synthetic cannabinoids in which we know exactly their affinity and intrinsic activity to different receptors. It appears that a combination of a CB1 agonist and a CB2 antagonist is likely to have the greatest antitumor effect. In addition, a dose of cannabinoid should be considered, since too low (inhibition of apoptosis) or too high (immunosuppression) cannabinoid doses, on the contrary, can lead to the progression of tumor growth and metastasis. The use of cannabinoids in combination with other chemotherapies has not only a synergistic effect, but also allows the dose of chemotherapeutics to be reduced and, therefore, to reduce the undesirable effects of anticancer therapies. In particular, the combination of cannabinoids with inhibitors of MDK/ALK and EGFR/ERK signaling pathways can have a great therapeutic effect. Unfortunately, most of the current data on antitumoral effects of cannabinoids come from in vitro studies or studies in animal models. Therefore, it is essential that the antitumor effect of cannabinoids (alone or in combination with another chemo/ radiotherapy) is identified in clinical trials.

\section{Reference}

1. Devane WA, Hanus L, Breuer A et al. Isolation and structure of a brain constituent that binds to the cannabinoid receptor. Science 1992; 258 (5090): 1946-1949.

2. Mechoulam R, Ben-Shabat S, Hanus $L$ et al. Identification of an endogenous 2-monoglyceride, present in canine gut, that binds to cannabinoid receptors. Biochem Pharmacol 1995; 50 (1): 83-90.

3. Sugiura T, Kondo S, Sukagawa A et al. 2-Arachidonoylglycerol: a possible endogenous cannabinoid receptor ligand in brain. Biochem Biophys Res Commun 1995; 215 (1): 89-97.

4. Matsuda LA, Lolait SJ, Brownstein MJ, Young AC, Bonner TI. Structure of a cannabinoid receptor and functional expression of the cloned cDNA. Nature 1990; 346 (6284): 561-564.

5. Munro S, Thomas KL, Abu-Shaar M. Molecular characterization of a peripheral receptor for cannabinoids. Nature 1993; 365 (6441): 61-65.

6. Pertwee RG, Howlett AC, Abood ME et al. International Union of Basic and Clinical Pharmacology. LXXIX. Cannabinoid receptors and their ligands: beyond CB1 and CB2. Pharmacol Rev 2010; 62 (4): 588-631.

7. Maida V, Daeninck PJ. A user's guide to cannabinoid therapies in oncology. Curr Oncol 2016; 23 (6): 398-406.

8. Nielsen S, Sabioni P, Trigo JM et al. Opioid-Sparing Effect of Cannabinoids: A Systematic Review and Meta-Analysis. Neuropsychopharmacology 2017; 42 (9): 1752-1765.

9. Stevens AJ, Higgins MD. A systematic review of the analgesic efficacy of cannabinoid medications in the management of acute pain. Acta Anaesthesiol Scand 2017; 61 (3): 268-280.
10. Brown AJ. Novel cannabinoid receptors. Br J Pharmacol 2007; 152 (5): $567-75$.

11. McHugh D, Hu SS, Rimmerman $\mathrm{N}$ et al. $\mathrm{N}$-arachidonoyl glycine, an abundant endogenous lipid, potently drives directed cellular migration through GPR18, the putative abnormal cannabidiol receptor. BMC Neurosci 2010; 11: 44 .

12. Pertwee RG. The pharmacology of cannabinoid receptors and thein ligands: an overview. Int J Obes 2006; 30 (1): 13-18.

13. Pagotto U, Marsicano G, Cota D, Lutz B, Pasquali R. The Emerging Role of the Endocannabinoid System in Endocrine Regulation and Energy Balance. Endocr Rev 2006; 27 (1): 73-100.

14. Goparaju SK, Ueda N, Yamaguchi H, Yamamoto S. Anandamide amidohydrolase reacting with 2-arachidonoylglycerol, another cannabinoid receptor ligand. FEBS Lett 1998; 422 (1): 69-73.

15. Dinh TP, Carpenter D, Leslie FM et al. Brain monoglyceride lipase participating in endocannabinoid inactivation. Proc Natl Acad Sci USA 2002; 99 (16): 10819-10824.

16. Pearson G, Robinson F, Beers Gibson $T$ et al. Mitogen-activated protein (MAP) kinase pathways: regulation and physiological functions. Endorr Rev 2001 Apr; 22(2): 153-183.

17. Osaki M, Oshimura M, Ito H. The PI3K-Akt pathway: Its functions and alterations in human cancer. Apoptosis 2004; 9 (6): 667-676.

18. Turcotte C, Blanchet MR, Laviolette M, Flamand $\mathbf{N}$. The $\mathrm{CB}_{2}$ receptor and its role as a regulator of inflammation. Cell Mol Life Sci 2016; 73: 4449-4470.

19. Bouaboula M, Poinot-Chazel C, Marchand J et al. Signaling pathway associated with stimulation of $\mathrm{CB} 2$ peripheral cannabinoid receptor. Involvement of both mitogen-activated protein kinase and induction of Krox-24 expression. Eur J Biochem 1996; 237 (3): 704-711.

20. Zoratti C, Kipmen-Korgun D, Osibow K, Malli R, Graier WF. Anandamide initiates $\mathrm{Ca} 2$ ? signaling via $\mathrm{CB} 2$ receptor linked to phospholipase C in calf pulmonary endothelial cells. Br J Pharmacol 2003; 140 (8): 1351-1362.

21. Moriconi A, Cerbara I, Maccarrone M, Topai A. GPR55: Current knowledge and future perspectives of a purported „Type-3“ cannabinoid receptor. Curr Med Chem 2010; 17 (14): 1411-1429.

22. Cherfils J, Zeghouf M. Regulation of small GTPases by GEFs, GAPs and GDIs. Physiol Rev 2013; 93 (1): 269-309.

23. Shan D, Chen L, Wang D, Tan YC, Gu JL, Huang XY. The G protein $\mathrm{G}$ alpha(13) is required for growth factor-induced cell migration. Dev Cell 2006; 10 (6): 707-718.

24. Lauckner JE, Jensen JB, Chen HY, Lu HC, Hille B, Mackie K. GPR55 is a cannabinoid receptor that increases intracellular calcium and inhibits M current. Proc Natl Acad Sci USA 2008; 105 (7): 2699-2704.

25. Wennerberg K, Rossman KL, Der CJ. The Ras superfamily at a glance. J Cell Sci 2005; 118 (5): 843-846.

26. Quadir MI, Parveen A, Ali M. CdC42: Role in Cancer Management. Chem Biol Drug Des 2015; 86 (4): 432-439.

27. Zhou C, Licciulli S, Avila JL et al. The Rac1 splice form Rac1b promotes K-ras-induced lung tumorigenesis. Oncogene 2013; 32 (7): 903-909.

28. Overton HA, Babbs AJ, Doel SM et al. Deorphanization of a G protein-coupled receptor for oleoylethanolamide and its use in the discovery of small-molecule hypophagic agents. Cell Metab 2006; 3 (3): $3167-3175$. 
29. Venkatachalam K, Montell C. TRP channels. Annu Rev Biochem 2007; 76: 387-417.

30. Soderstrom K, Soliman E, Van Dross R. Cannabinoids Modulate Neuronal Activity and Cancer by CB1 and CB2 Receptor-Independent Mechanisms. Front Pharmacol 2017 10; 8: 720.

31. Everaerts W, Gees M, Alpizar YA et al. The capsaicin receptor TRPV1 is a crucial mediator of the noxious effects of mustard oil. Curr Biol 2011; 21 (4): 316-321.

32. Starowicz K, Nigam S, Di Marzo V. Biochemistry and pharmacology of endovanilloids. Pharmacol Ther 2007; 114: 13-33.

33. Jordt SE, Julius D. Molecular basis for species-specific sensitivity to "hot" chili peppers. Cell 2002; 108: 421-430.

34. Starowicz K, Finn DP. Cannabinoids and Pain: Sites and Mechanism of Action. Adv Pharmacol 2017; 80: 437-475.

35. Pergolizzi JV Jr, Lequang JA, Taylor R Jr, Raffa RB, Colucci D. The role of cannabinoids in pain control: the good, the bad, and the ugly. Minerva Anestesiol 2018; 84 (8): 955-969.

36. Häuser W, Petzke F, Fitzcharles MA. Efficacy, tolerability and safety of cannabis-based medicines for chronic pain management-An overview of systematic reviews. Eur J Pain 2018; 22 (3): 455-470.

37. Mu A, Weinberg E, Moulin DE, Clarke H. Pharmacologic management of chronic neuropathic pain: Review of the Canadian Pain Society consensus statement. Can Fam Physician 2017; 63 (11): 844-852.

38. Krcevski-Skvarc N, Wells C, Häuser W. Availability and approval of cannabis-based medicine for chronic pain management and palliative/ supportive care in Europe: A survey of the status in the chapters of the European Pain Federation. Eur J Pain 2018; 22 (3): 440-454.

39. Zheng T, Zhang R, Zhang R et al. CB1 cannabinoid receptor agonist mouse VD-hemopressin $(\alpha)$ produced supraspinal analgesic activity in the preclinical models of pain. Brain Res 2018; 1680: 155-164.

40. Maguire DR, France CP. Antinociceptive effects of mixtures of mu opioid receptor agonist and cannabinoid receptor agonists in rats: Impact of drug and fixed-dose ratio. Eur J Pharmacol 2018; 819: 217-224

41. Cabeza C, Corsi O, Pérez-Cruz P. Are cannabinoids an alternative for cachexia-anorexia syndrome in patients with advanced cancer? Medwave 2017; 17 (9): e7130.

42. Morales M, Corsi $\mathbf{O}$, Peňa J. Are cannabinoids effective for the management of chemotherapy induced nauzea and vomiting? Medwave 2017; 17 (9): e7119.

43. Schussel V, Kenzo L, Santos A et al. Cannabinoids for nauzea and vomiting related to chemotherapy: Overview of systematic reviews. Phytother Res 2018; 32 (4): 567-576.

44. Abrams DI. The therapeutic effects of Cannabis and cannabinoids: An update from the National Academies of Sciences, Engineering and Medicine report. Eur J Interm Med 2018; 49: 7-11.

45. Velasco G, Hernández-Tiedra S, Dávila D, Lorente M. The use of cannabinoids as anticancer agents. Prog in Neuropsycho-pharmacol Biol Psychiatry 2016; 64: 259-266.

46. Velasco G, Sánchez C, Guzmán M. Towards the use of cannabinoids as antitumour agents. Nat Rev Cancer 2012; 12 (6): 436-44.

47. Bogdanovič V, Mrdjanovič J, Borišev I. A Review of the Therapeutic Antitumor Potential of Cannabinoids. J Altern Complement Med 2017; 23 (11): 831-836.
48. Remer R, Hinz B. Cannabinoids as Anticancer Drugs. Adv Pharmacol 2017; 80: 397-436.

49. Alexander A, Smith PF, Rosengren RJ. Cannabinoids in treatment of cancer. Cancer Lett 2009; 285 (1): 6-12.

50. Freimuth N, Ramer R, Hinz B. Antitumorigenic effects of cannabinoids beyond apoptosis. J Pharmacol Exp Ther 2010; 332 (2): 336-344.

51. Pisanti S, Picardi P, D'Alessandro A, Laezza C, Bifulco M. The endocannabinoid signaling system in cancer. Trends Pharmacol Sci 2013; 34 (5): 273-282.

52. Sarfaraz S, Adhami VM, Syed DN, Afag F, Mukhtar H. Cannabinoids for cancer treatment: progress and promise. Cancer Res 2008; 68 (2): 339-342.

53. Xie Z, Klionsky DJ. Autophagosome formation: core machinery and adaptations. Nature Cell Biology 2007; 9 (10): 1102-1109.

54. Mizushima N, Levin B, Cuervo AM, Klionsky DJ. Autophagy fights disease through cellular self-digestion. Nature 2008; 451: 1069-1075.

55. Maiuri MC, Zalckvar E, Kimchi, A, Kroemer G. Self-eating and self-killing: crosstalk between autophagy and apoptosis. Nat Rev Mol Cell Biol 2007; 8: 741-752.

56. Shrivastava A, Kuzontkoski PM, Groopman JE, Prasad A. Cannabidiol induces programmed cell death in breast cancer cells by coordinating the cross-talk between apoptosis and autophagy. Mol Cancer Ther 2011; 10 (7): 1161-72.

57. Salazar M, Carracedo A, Salanueva IJ et al. Cannabinoid action induces autophagy-mediated cell death through stimulation of ER stress in human glioma cells. J Clin Invest 2009; 119 (5): 1359-1372.

58. Vara D, Salazar M, Olea-Herrero N, Guzman M, Velasco G, DiazLaviada I. Antitumoral action of cannabinoids on hepatocellular carcinoma: role of AMPKdependent activation of autophagy. Cell Death Differ 2011; 18 (7): 1099-1111.

59. Armstrong JL, Hill DS, McKee CS et al. Exploiting cannabinoidinduced cytotoxic autophagy to drive melanoma cell death. J Invest Dermatol 2015; 135 (6): 1629-1637.

60. Cianchi F, Papucci L, Schiavone $\mathbf{N}$ et al. Cannabinoid receptor activation induces apoptosis through tumor necrosis factor alpha-mediated ceramide de novo synthesis in colon cancer cells. Clin Cancer Res 2008; 14 (23): 7691-7700.

61. Sánchez C, de Ceballos ML, del Pulgar TG et al. Inhibition of glioma growth in vivo by selective activation of the $\mathrm{CB}(2)$ cannabinoid receptor. Cancer Res 2001; 61: 5784-5789.

62. Carracedo A, Gironella M, Lorente $M$ et al. Cannabinoids induce apoptosis of pancreatic tumor cells via endoplasmic reticulum stress-related genes. Cancer Res 2006; 66 (13): 6748-6755.

63. Galve-Roperh I, Sánchez C, Cortés ML et al. Antitumoral action of cannabinoids: involvement of sustained ceramide accumulation and extracellular signal-regulated kinase activation. Nat Med 2000; 6: 255-256.

64. Guzmán M, Galve-Roperh I,Sánchez C. Ceramide: a new second messenger of cannabinoid action. Trends Pharmacol Sci 2001; 22: 19-22.

65. Carracedo A, Lorente M, Egia A et al. The stress-regulated protein p8 mediates cannabinoid induced apoptosis of tumor cells. Cancer Cell 2006; 9: 301-312.

66. Herrera B, Carracedo A, Diez-Zaera M et al. CB2 cannabinoid receptor signals apoptosis via ceramide-dependent activation of the mitochondrial intrinsic pathway. Exp Cell Res 2006; 312: 2121-2131. 
67. Rozpędek W, Pytel D, Mucha B, Leszczyńska H, Alan Diehl J, Majsterek I. The Role of the PERK/eIF2 $\alpha /$ ATF4/CHOP Signaling Pathway in Tumor Progression During Endoplasmic Reticulum Stress. Curr Mol Med 2016; 16 (6): 533-544.

68. Guertin DA, Sabatini DM. Defining the role of mTOR in cancer. Cancer Cell 2007; 12: 9-22.

69. Dando I, Donadelli M, Costanzo $\mathrm{C}$ et al. Cannabinoids inhibit energetic metabolism and induce AMPK-dependent autophagy in pancreatic cancer cells. Cell Death Dis 2013; 4: e664.

70. Massi P, Valenti M, Vaccani A et al. 5-Lipoxygenase and anandamide hydrolase (FAAH) mediate the antitumor activity of cannabidiol, a nonpsychoactive cannabinoid. J Neurochem 2008; 104 (4): 1091-1100.

71. Hsu H, Xiong J, Goeddel DV. The TNF receptor 1-associated protein TRADD signaling cell death and NF-kappa B activation. Cell 1995; 81 (4): 495-504.

72. Wei MC, Lindsten T, Mootha VK et al. tBID, a membrane-targeted death ligand, oligomerizes BAK to release cytochrome c. Genes Dey 2000; 14 (16): 2060-2071.

73. Caffarel MM, Sarrio D, Palacios J, Guzman M, Sanchez C. Delta9-tetrahydrocannabinol inhibits cell cycle progression in human breast cancer cell through Cdc2 regulation. Cancer Res 2006; 66: 6615-6621.

74. Blázquez C, Carracedo A, Barrado $L$ et al. Cannabinoid receptors as novel targets for the treatment of melanoma. FASEB J 2006; 20 (14): 2633-2635.

75. Caffarel MM, Moreno-Bueno G, Cerutti C et al. JunD is involved in the antiproliferative effect of Delta9-tetrahydrocannabinol on human breast cancer cells. Oncogene 2008; 27 (37): 5033-44.

76. Rafalski VA, Brunet A. Energy metabolism in adult neural stem cell fate. Prog Neurobiol 2011; 93 (2): 182-203.

77. Ellert-Miklaszewska A, Kaminska B, Konarska L. Cannabinoids down-regulate PI3K/Akt and Erk signalling pathways and activate proapoptotic function of Bad protein. Cell Signal 2005; 17 (1): 25-37.

78. Orton RJ, Sturm OE, Vyshemirsky V, Calder M, Gilbert DR, Kolch W. Computational modelling of the receptor-tyrosine-kinase-activated MAPK pathway. Biochem J 2005; 392 (2): 249-261.

79. Avruch J, Khokhlatchev A, Kyriakis JM et al. Ras activation of the Raf kinase: tyrosine kinase recruitment of the MAP kinase cascade. Recent Prog Horm Res 2001; 56 (1): 127-155.

80. Piňeiro R, Maffucci T, Falasca M. The putative cannabinoid receptor GPR55 defines a novel autocrine loop in cancer cell proliferation. Oncogene 2011; 30: 142-152

81. Andradas C, Caffarel MM, Pérez-Gómez E et al. The orphan G protein-coupled receptor GPR55 promotes cancer cell proliferation via ERK. Oncogene 2011; 30: 245-252.

82. Lorente M, Carracedo A, Torres S et al. Amphiregulin is a factor for resistance of glioma cells to cannabinoid-induced apoptosis. Glia 2009; 57 (13): 1374-85.

83. Ravi J, Sneh A, Shilo K, Nasser MW, Ganju RK. FAAH inhibition enhances anandamide mediated anti-tumorigenic effects in non-small cell lung cancer by downregulating the EGF/EGFR pathway. Oncotarget. 2014; 5 (9): 2475-2486.

84. Ravi J, Elbaz M, Wani NA, Nasser MW, Ganju RK. Cannabinoid receptor-2 agonist inhibits macrophage induced EMT in non-small cell lung cancer by downregulation of EGFR pathway. Mol Carcinog. 2016; 55 (12): 2063-2076.
85. Keresztes A, Streicher JM. Synergistic interaction of the cannabinoid and death receptor system - a potential target for future cancer therapies? FEBS Lett 2017; 591 (20): 3235-3251.

86. DeMorrow S, Glaser S, Francis $\mathbf{H}$ et al. Opposing actions of endocannabinoids on cholangiocarcinoma growth: recruitment of Fas and Fas ligand to lipid rafts. J Biol Chem 2007; 282 (17): 13098-13113.

87. Huang L, Ramirez JC, Frampton GA et al. Anandamide exerts its antiproliferative actions on cholangiocarcinoma by activation of the GPR55 receptor. Lab Invest 2011; 91 (7): 1007-1017.

88. Ramer R, Heinemann K, Merkord $\mathbf{J}$ et al. COX-2 and PPAR- $\gamma$ confer cannabidiol-induced apoptosis of human lung cancer cells. Mol Cancer Ther 2013; 12 (1): 69-82.

89. Qamri Z, Preet A, Nasser MW et al. Synthetic cannabinoid receptor agonists inhibit tumor growth and metastasis of breast cancer. Mol Cancer Ther 2009; 8 (11): 3117-3129.

90. Casanova ML, Blázquez C, Martínez-Palacio J et al. Inhibition of skin tumor growth and angiogenesis in vivo by activation of cannabinoid receptors. J Clin Invest 2003; 111 (1): 43-50.

91. Solinas M, Massi P, Cantelmo AR et al. Cannabidiol inhibits angiogenesis by multiple mechanisms. Br J Pharmacol 2012 ; 167 (6): 12181231.

92. Laezza C, Malfitano AM, Proto MC et al. Inhibition of 3-hydroxy3-methylglutaryl-coenzyme A reductase activity and of Ras farnesylation mediate antitumor effects of anandamide in human breast cancer cells. Endocr Relat Cancer 2010; 17 (2): 495-503.

93. Blázquez C, Salazar M, Carracedo A et al. Cannabinoids inhibit glioma cell invasion by down-regulating matrix metalloproteinase-2 expression. Cancer Res 2008; 68 (6): 1945-1952.

94. Ramer R, Merkord J, Rohde H, Hinz B. Cannabidiol inhibits cancer cell invasion via upregulation of tissue inhibitor of matrix metalloproteinases-1. Biochem Pharmacol. 2010; 79 (7): 955-966.

95. Coke CJ, Scarlett KA, Chetram MA et al. Simultaneous Activation of Induced Heterodimerization between CXCR4 Chemokine Receptor and Cannabinoid Receptor 2 (CB2) Reveals a Mechanism for Regulation of Tumor Progression. J Biol Chem 2016; 291 (19): 9991-10005.

96. Ramer R, Rohde A, Merkord J, Rohde H, Hinz B. Decrease of plasminogen activator inhibitor-1 may contribute to the anti-invasive action of cannabidiol on human lung cancer cells. Pharm Res 2010; 27 (10): $2162-2174$

97. Blázquez C, González-Feria L, Alvarez L, Haro A, Casanova ML, Guzmán M. Cannabinoids inhibit the vascular endothelial growth factor pathway in gliomas. Cancer Res 2004; 64 (16): 5617-5623.

98. McKallip RJ, Nagarkatti M, Nagarkatti PS. Delta-9-tetrahydrocannabinol enhances breast cancer growth and metastasis by suppression of the antitumor immune response. J Immunol 2005; 174: 3281-3289.

99. Lavon I, Sheinin T, Meilin S et al. A novel synthetic cannabinoid derivative inhibits inflammatory liver damage via negative cytokine regulation. Mol Pharmacol 2003; 64 (6): 1334-1341.

100. Zhu LX, Sharma S, Stolina M et al. Delta-9-tetrahydrocannabinol inhibits antitumour immunity by a cb2 receptormediated, cytokine-dependent pathway. J Immunol 2000; 165: 373-380.

101. Hegde VL, Nagarkatti M, Nagarkatti PS. Cannabinoid receptor activation leads to massive mobilization of myeloid-derived suppressor cells with potent immunosuppressive properties. Eur J Immunol 2010; 40 (12): $3358-3371$. 
102. Hegde VL, Singh UP, Nagarkatti PS, Nagarkatti M. Critical role of mast cells and peroxisome proliferator-activated receptor gamma (PPAR $\gamma$ ) in the induction of myeloid-derived suppressor cells by marijuana cannabidiol in vivo. J Immunol 2015; 194 (11): 5211-5222.

103. Liu WM, Fowler DW, Dalgleish AG. Cannabis-derived substances in cancer therapy - an emerging anti-inflammatory role for the cannabinoids. Curr Clin Pharmacol 2010; 5: 281-287.

104. Xiang W, Shi R, Kang $X$ et al. Monoacylglycerol lipase regulates cannabinoid receptor 2-dependent macrophage activation and cancer progression. Nat Commun 2018; 9 (1): 2574.

105. Haustein M, Ramer R, Linnebacher M, Manda K, Hinz B. Cannabinoids increase lung cancer cell lysis by lymphokine-activated killer cells via upregulation of ICAM-1. Biochem Pharmacol 2014; 92 (2): 312-325.

106. Ramer R, Bublitz K, Freimuth $\mathbf{N}$ et al. Cannabidiol inhibits lung cancer cell invasion and metastasis via intercellular adhesion molecule-1. FASEB J 2012; 26 (4): 1535-1548.

107. Torres S, Lorente M, Rodríguez-Fornés $\mathbf{F}$ et al. A combined preclinical therapy of cannabinoids and temozolomide against glioma. Mol Cancer Ther 2011; 10 (1): 90-103.

108. Donadelli M, Dando I, Zaniboni T et al. Gemcitabine/cannabinoid combination triggers autophagy in pancreatic cancer cells through a ROSmediated mechanism. Cell Death Dis 2011; 2: e152

109. Miyato H, Kitayama J, Yamashita $H$ et al. Pharmacological synergism between cannabinoids and paclitaxel in gastric cancer cell lines. J Surg Res 2009; 155 (1): 40-47.

110. De Petrocellis L, Ligresti A, Schiano Moriello A et al. Non-THC cannabinoids inhibit prostate carcinoma growth in vitro and in vivo: proapoptotic effects and underlying mechanisms. Br J Pharmacol 2013; 168 (1): 79-102.

111. Gustafsson SB, Lindgren T, Jonsson M, Jacobsson SO. Cannabinoid receptor-independent cytotoxic effects of cannabinoids in human colorectal carcinoma cells: synergism with 5-fluorouracil. Cancer Chemother Pharmacol 2009; 63 (4): 691-701.

112. Lorente M, Torres S, Salazar M et al. Stimulation of the midkine/ ALK axis renders glioma cells resistant to cannabinoid antitumoral action. Cell Death Differ 2011; 18 (6): 959-973.

113. Hohmann T, Grabiec U, Ghadban C, Feese K, Dehghani F. The influence of biomechanical properties and cannabinoids on tumor invasion. Cell Adh Migr 2017; 11 (1): 54-67.

114. Salazar M, Carracedo A, Salanueva IJ et al. Cannabinoid action induces autophagy-mediated cell death through stimulation of ER stress in human glioma cells. J Clin Invest 2009; 119 (5): 1359-1372.

115. Ivanov VN, Wu J, Hei TK. Regulation of human glioblastoma cell death by combined treatment of cannabidiol, $\gamma$-radiation and small molecule inhibitors of cell signaling pathways. Oncotarget 2017; 8 (43): 74068-74095.

116. Hernán Pérez de la Ossa D, Lorente M, Gil-Alegre ME et al. Local delivery of cannabinoid-loaded microparticles inhibits tumor growth in a murine xenograft model of glioblastoma multiforme. PLoS One 2013; 8 (1): e54795.

117. Sánchez C, de Ceballos ML, Gomez del Pulgar T et al. Inhibition of glioma growth in vivo by selective activation of the $\mathrm{CB}(2)$ cannabinoid receptor. Cancer Res 2001; 61 (15): 5784-5789.

118. Gurley SN, Abidi AH, Allison $P$ et al. Mechanism of anti-glioma activity and in vivo efficacy of the cannabinoid ligand KM-233. J Neurooncol 2012; 110 (2): 163-177.
119. Massi P, Vaccani A, Ceruti S, Colombo A, Abbracchio MP, Parolaro D. Antitumor effects of cannabidiol, a nonpsychoactive cannabinoid, on human glioma cell lines. J Pharmacol Exp Ther 2004; 308 (3): 838-845.

120. Blázquez C, Casanova ML, Planas A et al. Inhibition of tumor angiogenesis by cannabinoids. FASEB J 2003; 17 (3): 529-531.

121. Aguado T, Carracedo A, Julien B et al. Cannabinoids induce glioma stem-like cell differentiation and inhibit gliomagenesis. J Biol Chem 2007; 282 (9): 6854-6862.

122. Singer E, Judkins $\mathbf{J}$, Salomonis $\mathbf{N}$ et al. Reactive oxygen speciesmediated therapeutic response and resistance in glioblastoma. Cell Death Dis 2015; 6: e1601.

123. Scott KA, Dalgleish AG, Liu WM. The combination of cannabidiol and $\Delta 9$-tetrahydrocannabinol enhances the anticancer effects of radiation in an orthotopic murine glioma model. Mol Cancer Ther 2014; 13 (12): 2955-2967.

124. Martínez-Martínez E, Gómez I, Martín P et al. Cannabinoids receptor type 2, CB2, expression correlates with human colon cancer progression and predicts patient survival. Oncoscience 2015; 2 (2): 131-141.

125. Martínez-Martínez E, Martín-Ruiz A, Martín P, Calvo V, Provencio M, García JM. CB2 cannabinoid receptor activation promotes colon cancer progression via AKT/GSK3 $\beta$ signaling pathway. Oncotarget 2016; 7 (42): 68781-68791.

126. Aviello G, Romano B, Borrelli F et al. Chemopreventive effect of the non-psychotropic phytocannabinoid cannabidiol on experimental colon cancer J Mol Med (Berl) 2012; 90 (8): 925-934.

127. Romano B, Borrelli F, Pagano E, Cascio MG, Pertwee RG, Izzo AA. Inhibition of colon carcinogenesis by a standardized Cannabis sativa extract with high content of cannabidiol. Phytomedicine 2014; 21 (5): 631-639.

128. Borrelli F, Pagano E, Romano B et al. Colon carcinogenesis is inhibited by the TRPM8 antagonist cannabigerol, a Cannabis-derived nonpsychotropic cannabinoid. Carcinogenesis 2014; 35 (12): 2787-2797.

129. Kogan NM, Blázquez $C$, Alvarez $L$ et al. A cannabinoid quinone inhibits angiogenesis by targeting vascular endothelial cells. Mol Pharmacol 2006; 70 (1): 51-59.

130. Kogan NM, Schlesinger M, Peters M, Marincheva G, Beeri R, Mechoulam R. A cannabinoid anticancer quinone, HU-331, is more potent and less cardiotoxic than doxorubicin: a comparative in vivo study. J Pharmacol Exp Ther 2007; 322 (2): 646-653.

131. Kargl J, Haybaeck J, Stančić A et al. O-1602, an atypical cannabinoid, inhibits tumor growth in colitisassociated colon cancer through multiple mechanisms. J Mol Med (Berl) 2013; 91 (4): 449-458.

132. Sreevalsan S, Joseph S, Jutooru I, Chadalapaka G, Safe SH. Induction of apoptosis by cannabinoids in prostate and colon cancer cells is phosphatase dependent. Anticancer Res 2011; 31 (11): 3799-3807.

133. Athanasiou A, Clarke AB, Turner AE et al. Cannabinoid receptor agonists are mitochondrial inhibitors: a unified hypothesis of how cannabinoids modulate mitochondrial function and induce cell death. Biochem Biophys Res Commun 2007; 364 (1): 131-137.

134. Preet A, Ganju RK, Groopman JE. Delta9-Tetrahydrocannabinol inhibits epithelial growth factor-induced lung cancer cell migration in vitro as well as its growth and metastasis in vivo. Oncogene 2008; 27 (3): 339-346.

135. Preet A, Qamri Z, Nasser MW et al. Cannabinoid receptors, $C B 1$ and $\mathrm{CB} 2$, as novel targets for inhibition of non-small cell lung cancer growth and metastasis. Cancer Prev Res (Phila) 2011; 4 (1): 65-75. 
136. Vidinský $\mathbf{B}$, Gál $P$, Pilátová $M$ et al. Anti-proliferative and antiangiogenic effects of CB2R agonist (JWH-133) in non-small lung cancer cells (A549) and human umbilical vein endothelial cells: an in vitro investigation. Folia Biol (Praha) 2012; 58 (2): 75-80.

137. Gardner B, Zhu LX, Sharma S, Tashkin DP, Dubinett SM. Methanandamide increases COX-2 expression and tumor growth in murine lung cancer. FASEB J 2003; 17 (14): 2157-2159.

138. Elbaz M, Nasser MW, Ravi J et al. Modulation of the tumor microenvironment and inhibition of EGF/EGFR pathway: novel anti-tumor mechanisms of Cannabidiol in breast cancer. Mol Oncol 2015; 9 (4): 906-919.

139. Grimaldi C, Pisanti S, Laezza $C$ et al. Anandamide inhibits adhesion and migration of breast cancer cells. Exp Cell Res 2006; 312 (4): 363-373.

140. Mohammadpour F, Ostad SN, Aliebrahimi S, Daman Z. Anti-invasion Effects of Cannabinoids Agonist and Antagonist on Human Breast Cancer Stem Cells. Iran J Pharm Res 2017; 16 (4): 1479-1486.

141. Murase R, Kawamura R, Singer $\mathbf{E}$ et al. Targeting multiple cannabinoid anti-tumour pathways with a resorcinol derivative leads to inhibition of advanced stages of breast cancer. Br J Pharmacol 2014; 171 (19): 4464-4477.

142. Sophocleous A, Marino S, Logan JG, Mollat P, Ralston SH, Idris AI. Bone Cell-autonomous Contribution of Type 2 Cannabinoid Receptor to Breast Cancer-induced Osteolysis. J Biol Chem 2015; 290 (36): 22049-22060.

143. Ligresti A, Moriello AS, Starowicz K et al. Antitumor activity of plant cannabinoids with emphasis on the effect of cannabidiol on human breast carcinoma J Pharmacol Exp Ther 2006; 318 (3): 1375-1387.

144. McAllister SD, Murase R, Christian RT et al. Pathways mediating the effects of cannabidiol on the reduction of breast cancer cell proliferation, invasion, and metastasis. Breast Cancer Res Treat 2011; 129 (1): 37-47.

145. Caffarel MM, Andradas C, Mira E et al. Cannabinoids reduce ErbB2-driven breast cancer progression through Akt inhibition. Mol Cancer 2010; 9: 196

146. Nasser MW, Qamri Z, Deol YS et al. Crosstalk between chemokine receptor CXCR4 and cannabinoid receptor $\mathrm{CB} 2$ in modulating breast cancer growth and invasion. PLoS One 2011; 6 (9): e23901.

147. Laezza C, Pisanti S, Crescenzi E, Bifulco M. Anandamide inhibits Cdk2 and activates Chk1 leading to cell cycle arrest in human breast cancer cells. FEBS Lett 2006; 580 (26): 6076-6082.

148. Laezza C, Pisanti S, Malfitano AM, Bifulco M. The anandamide analog, Met-F-AEA, controls human breast cancer cell migration via the RHOA/RHO kinase signaling pathway. Endocr Relat Cancer 2008; 15 (4): 965-974.

149. Olea-Herrero N, Vara D, Malagarie-Cazenave S, Díaz-Laviada I. Inhibition of human tumor prostate PC-3 cell growth by cannabinoids $\mathrm{R}(+)$ - Methanandamide and JWH-015: Involvement of CB2. Br J Cancer 2009; 101: 940-950.

150. Ruiz L, Miguel A, Díaz-Laviada I. Delta9-tetrahydrocannabinol induces apoptosis in human prostate PC-3 cells via a receptor-independent mechanism. FEBS Lett 1999; 458 (3): 400-404.

151. Sarfaraz S, Afaq F, Adhami VM, Malik A, Mukhtar H. Cannabinoid receptor agonist-induced apoptosis of human prostate cancer cells LNCaP proceeds through sustained activation of ERK1/2 leading to G1 cell cycle arrest. J Biol Chem 2006; 281 (51): 39480-39491.
152. Nithipatikom K, Gomez-Granados AD, Tang AT, Pfeiffer AW, Williams CL, Campbell WB. Cannabinoid receptor type 1 (CB1) activation inhibits small GTPase RhoA activity and regulates motility of prostate carcinoma cells. Endocrinology 2012; 153 (1): 29-41.

153. Khan MI, Sobocińska AA, Brodaczewska KK et al. Involvement of the $\mathrm{CB}_{2}$ cannabinoid receptor in cell growth inhibition and $\mathrm{G} 0 / \mathrm{G} 1$ cell cycle arrest via the cannabinoid agonist WIN 55,212-2 in renal cell carcinoma. BMC Cancer 2018; 18 (1): 583.

154. Bifulco M, Laezza C, Portella G et al. Control by the endogenous cannabinoid system of ras oncogene-dependent tumor growth. FASEB J 2001; 15 (14): 2745-2747.

155. Bifulco M, Laezza C, Valenti M, Ligresti A, Portella G, DI Marzo V. A new strategy to block tumor growth by inhibiting endocannabinoid inactivation. FASEB J 2004; 18 (13): 1606-1608.

156. Vara D, Morell C, Rodríguez-Henche N, Diaz-Laviada I. Involvement of PPAR $\gamma$ in the antitumoral action of cannabinoids on hepatocellular carcinoma. Cell Death Dis 2013; 4: e618.

157. DeMorrow S, Francis $\mathbf{H}$, Gaudio $\mathbf{E}$ et al. The endocannabinoid anandamide inhibits cholangiocarcinoma growth via activation of the noncanonical Wnt signaling pathway. Am J Physiol Gastrointest Liver Physiol 2008; 295 (6): G1150-1158.

158. Xian X, Huang L, Zhang B, Wu C, Cui J, Wang Z. WIN 55,212-2 Inhibits the Epithelial Mesenchymal Transition of Gastric Cancer Cells via COX-2 Signals. Cell Physiol Biochem 2016; 39 (6): 2149-2157.

159. Fonseca BM, Correia-da-Silva G, Teixeira NA. Cannabinoid-induced cell death in endometrial cancer cells: involvement of TRPV1 receptors in apoptosis. J Physiol Biochem 2018; 74 (2): 261-272.

160. Zhang Y, Zheng W, Shen K, Shen W. $\Delta 9$-tetrahydrocannabinol inhibits epithelial-mesenchymal transition and metastasis by targeting matrix metalloproteinase-9 in endometrial cancer. Oncol Lett 2018; 15 (6): $8527-8535$.

161. Glodde N, Jakobs M, Bald T, Tüting T, Gaffal E. Differential role of cannabinoids in the pathogenesis of skin cancer. Life Sci 2015; 138: 35-40.

162. Blázquez C, Carracedo A, Barrado L et al. Cannabinoid receptors as novel targets for the treatment of melanoma. FASEB J 2006; 20 (14): 2633-2635.

163. Nakajima J, Nakae D, Yasukawa K. Structure-dependent inhibitory effects of synthetic cannabinoids against 12-O-tetradecanoylphorbol13-acetate-induced inflammation and skin tumour promotion in mice. $\mathrm{J}$ Pharm Pharmacol 2013; 65 (8): 1223-1230.

164. Capozzi A, Mattei V, Martellucci S et al. Anti-Proliferative Properties and Proapoptotic Function of New CB2 Selective Cannabinoid Receptor Agonist in Jurkat Leukemia Cells. Int J Mol Sci 2018; 19 (7): 1958.

165. McKallip RJ, Lombard C, Fisher $M$ et al. Targeting CB2 cannabinoid receptors as a novel therapy to treat malignant lymphoblastic disease. Blood 2002; 100 (2): 627-634.

166. Nabissi M, Morelli MB, Offidani M et al. Cannabinoids synergize with carfilzomib, reducing multiple myeloma cells viability and migration. Oncotarget 2016; 7 (47): 77543-77557.

167. Freund P, Porpaczy EA, Le T et al. Cannabinoid Receptors Are Overexpressed in CLL but of Limited Potential for Therapeutic Exploitation. PLoS One 2016; 11 (6): e0156693. 